\title{
The role of microRNAs in lymphopoiesis
}

\author{
Timothy M. Johanson - Jarrod P. J. Skinner • \\ Amit Kumar · Yifan Zhan - Andrew M. Lew • \\ Mark M. W. Chong
}

Received: 30 April 2014/Revised: 12 May 2014/ Accepted: 26 May 2014/Published online: 15 June 2014

(c) The Japanese Society of Hematology 2014

\begin{abstract}
The immune system is composed of a diverse range of cell types, each with a distinct function. It can be broadly divided into the lymphoid (T, B, NK, etc.) and myeloid (monocyte, granulocyte, etc.) arms. Lymphopoiesis, the development and differentiation of lymphoid lineages, has been studied extensively for decades. For example, the influence of extracellular signals, signaling pathways and transcription factors has already been well documented. However, the importance of microRNAs has been highlighted by a surge of studies in recent years. In this review, we will discuss what is currently known about the role of microRNAs in lymphopoiesis, from the hematopoietic stem cell through to the differentiation of mature lymphocytes including thymic development, helper and regulatory $\mathrm{T}$ cells, fate determination of $\mathrm{B}$ cells and dendritic cells.
\end{abstract}

Keywords Lymphopoiesis - Lymphocytes - MicroRNA

T. M. Johanson · J. P. J. Skinner · A. Kumar .

M. M. W. Chong ( $\square)$

St Vincent's Institute of Medical Research, Fitzroy, VIC,

Australia

e-mail: mchong@svi.edu.au

T. M. Johanson · Y. Zhan · A. M. Lew

Walter and Eliza Hall Institute of Medical Research, Parkville,

VIC, Australia

T. M. Johanson - Y. Zhan · A. M. Lew

Department of Medical Biology, University of Melbourne,

Parkville, VIC, Australia

M. M. W. Chong

Department of Medicine (St Vincent's), University of

Melbourne, Fitzroy, VIC, Australia

\section{Introduction}

MicroRNAs (miRNAs) are $\sim 22$ nucleotide small non-coding RNA molecules. Discovery of the first miRNA, lin-4, followed from a genetic screen for developmental mutants in the embryo of the nematode $C$. elegans [1,2]. MiRNAs have since been identified in all plants and animals, and are also encoded by some viruses. As of 2014, over 24 thousand miRNAs have been discovered across 206 species [3].

MiRNAs affect gene expression via complementary base pairing with target messenger RNAs (mRNAs). Due to their small size, multiple miRNAs can simultaneously bind to a single target mRNA, while each miRNA can potentially bind to multiple different mRNAs [4]. It is predicted that up to $60 \%$ of human mRNAs can be recognized by miRNAs [5]. Thus, mRNA-miRNA interactions have an enormous impact on the regulation of gene expression and ultimately the function of any cell. This realization led to the rapid development of an array of animal models and other tools for studying the miRNA pathway. Mouse models harboring mutations in common pathway components implicated roles for miRNAs in the immune system early on. Investigations have since focused on the function of individual miRNAs. It is now clear that the development and function of the immune system are highly dependent on miRNA-mediated gene regulation.

\section{The microRNA pathway}

MiRNAs recognize mRNAs as part of the RNA-induced silencing complex (RISC). At the core of this complex is one of four members of the Argonaute family of proteins, Ago1-4 [6, 7]. MiRNAs primarily interact with $3^{\prime}$ untranslated regions of mRNAs [8,9]. As little as seven 


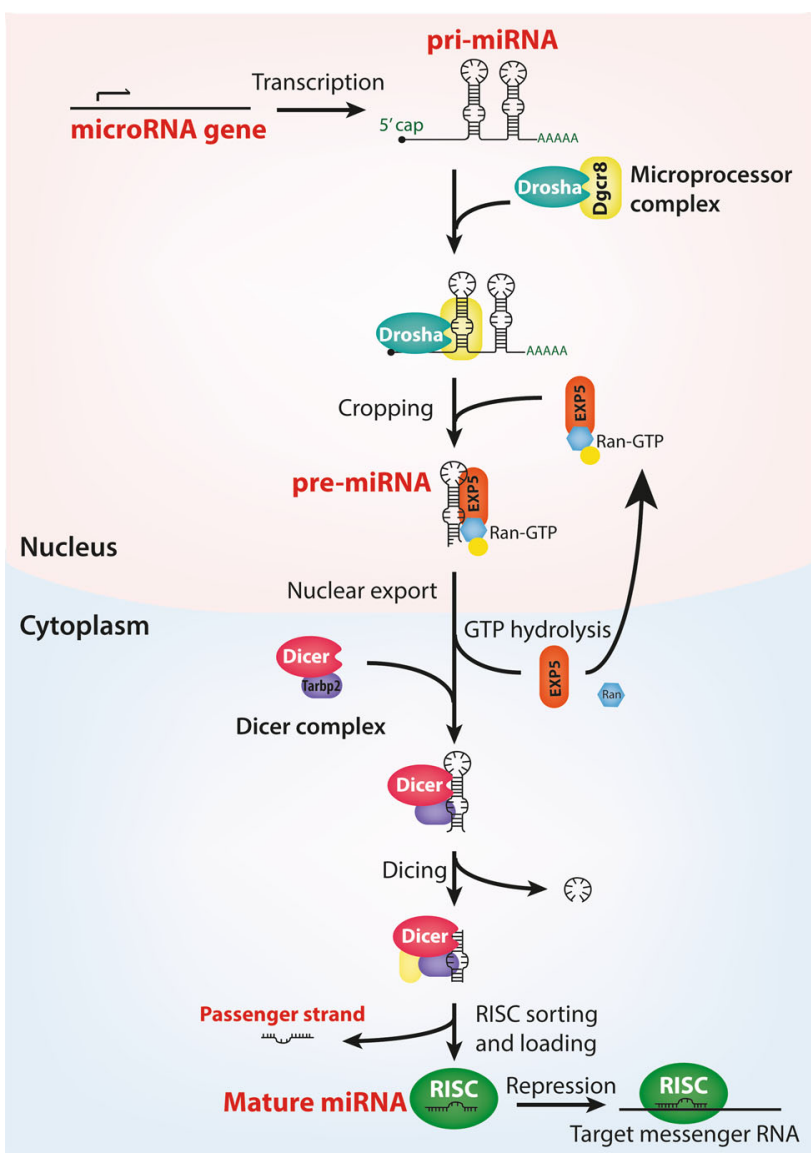

Fig. 1 MiRNA biogenesis. The biogenesis of miRNAs in animals is dependent on processing of precursors by two RNase III enzyme complexes. Long primary transcriptions are first cleaved by Drosha in the nucleus to release the pre-miRNA stem-loop intermediate. This pre-miRNA is then processed by Dicer in the cytoplasm to release the mature miRNA for loading into the effector RISC. Both Drosha and Dicer function as part of large complexes containing cofactors and other regulators, including dsRNA-binding proteins such as Dgcr8 and Trbp2

base pairs at the $5^{\prime}$ end of the miRNA (known as the seed sequence) are sufficient for targeting in animals [10]. Once bound to the mRNA, miRNAs can affect expression via multiple mechanisms, such as by interfering with initiation or ribosome processivity, or causing mRNA decapping and deadenylation [11].

miRNAs are derived from short stem-loop structures imbedded within long primary transcripts (pri-miRNA). Like other genes, most pri-miRNAs are transcribed as independent units from DNA. However, up to $40 \%$ of miRNAs are derived from introns spliced out from mRNAs. Maturation of miRNAs from either independent transcriptional units or introns requires the activity of two enzyme complexes (Fig. 1). This initial long primary miRNA (primiRNA) is first processed by the nuclear "microprocessor" complex, containing the RNase III endonuclease Drosha and a dsRNA-binding protein Dgcr8 (also known as Pasha in
D. melanogaster and C. elegans) [12-14]. This complex cleaves both strands of the stem-loop near the base to release a pre-miRNA intermediate. The pre-miRNA is then exported to the cytoplasm, where it is processed by a complex containing another RNase III enzyme, Dicer, and the dsRNAbinding protein Tarbp2, to remove the loop $[15,16]$. This leaves a $\sim 22$ bp miRNA:miRNA* duplex. Tarbp2 then facilitates the loading of one of these strands into the RISC, while the other strand is degraded.

\section{Regulation of hematopoietic stem cell function}

The delicate balance between self-renewal and differentiation of hematopoietic stem cells (HSCs) is critical for maintaining proper hematopoiesis. This is primarily sustained by transcription factors that act as master regulators of gene expression. However, miRNAs constitute another critical layer of regulation.

A likely role for miRNAs in the regulation of hematopoiesis was realized quite early, when it was shown that overexpression of miR-181a in bone marrow promotes the differentiation of B cells [17]. In fact, this was one of the first evidence of a function for miRNAs in mammals. Disruption of the miRNA pathway in HSCs, by deletion of machinery components, impairs the repopulation capacity of these cells, leading to bone marrow failure [18, 19].

Several miRNAs have been implicated in the regulation of HSC self-renewal. miR-29a [20] and miR-196b [21] are both highly expressed by HSCs and their downregulation is associated with differentiation. They are thought to regulate selfrenewal, because overexpression induces various leukemias. $\mathrm{miR}-125 \mathrm{a} / \mathrm{b}$, the mammalian homologs of lin-4, are also highly expressed in HSCs, and downregulated with differentiation [18, 22]. Both appear to promote HSC self-renewal by regulating apoptotic targets. Bak is regulated by miR-125a [18], while Bmf and Klf13 are regulated by miR-125b [22].

Indicative of the breadth of influence that miRNAs exert early in hematopoiesis, many of these miRNAs that regulate HSC self-renewal also influence hematopoietic differentiation. Forced expression of miR-125a promotes B lymphopoiesis [18], whereas forced expression of miR-29a [20] or miR-125b [22] promotes myelopoiesis. How these miRNAs preference lymphopoiesis versus myelopoiesis is unclear, but forced expression of the latter two ultimately leads to myeloid leukemia as a result of imparting HSClike self-renewal properties.

\section{Regulation of $\mathbf{T}$ cell development in the thymus}

$\mathrm{T}$ cells develop in the thymus from progenitors that travel from the bone marrow. Early thymocytes first progress 


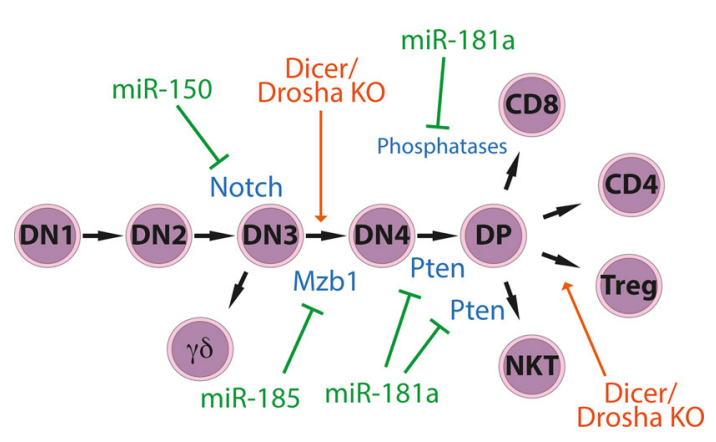

Fig. 2 MiRNA regulation of $\mathrm{T}$ lymphopoiesis. MiRNAs play important roles throughout $\mathrm{T}$ cell development. Indicated are miRNAs and their targets that are known to contribute to control of this developmental pathway. Also shown are developmental blocks caused by Drosha or Dicer deficiency. $D N$ double negative, $D P$ double positive

through a series of four stages termed double negative (DN), as they lack expression of the CD4 and CD8 coreceptors. The DN3 stage is where $\gamma \delta \mathrm{T}$ cells bifurcate from the $\alpha \beta T$ cell lineages. DN4 cells then upregulate both $\mathrm{CD} 4{ }^{+} 8^{+}$thus becoming double positive (DP). Selection then leads to the differentiation of CD8 single positive (SP) cytotoxic T cells, CD4 SP helper T cells, NKT cells or one of several other possible lineages depending on the specificity and affinity of the expressed T cell receptor (TCR). miRNAs appear to be important at many stages throughout T cell development (Fig. 2).

Initial characterization of mice in which the Dicerl gene was deleted in early thymocytes using an Lck-cre transgene, suggested that the miRNA pathway might not be required [23]. This was despite an apparent tenfold reduction in thymocyte numbers. However, a later study confirmed that the miRNA pathway is indeed necessary for $\mathrm{T}$ cell development. Deletion of the genes encoding either Dicer or Drosha early in $\mathrm{T}$ cell development results in a developmental block at the DN3 stage [24]. This corresponds to the TCR $\beta$ rearrangement checkpoint, when productive rearrangement is required for progression to DN4. On the other hand, there was an accumulation of $\gamma \delta \mathrm{T}$ cells in these mice, indicating a requirement of miRNAs only for $\alpha \beta T$ cell development. Deletion of either Dicerl or Drosha late in T cell development has a less severe impact, resulting in a twofold reduction in mature cell numbers $[25,26]$.

The specific miRNAs that are necessary for $\mathrm{T}$ cell development are still not clear, but it is likely that multiple miRNAs are involved at different stages. miR-150 may be one that is important for the early checkpoint. The Notch pathway is important for $\mathrm{T}$ cell development, playing important functions throughout the lineage, but particularly in DN thymocytes [27]. Notch3 is a target of miR-150 in T cells [28], and the interplay between the two may be important. Transgenic expression of miR-185 impairs the progression to the DP stage by targeting Mzb1 [29], but whether endogenous miR-185 is important for $\mathrm{T}$ cell development remains to be determined.

miR-181a and other miR-181 members are very abundant at the DP stage, comprising as much as half the miRNA molecules expressed [26, 30]. Overexpression of miR-181a results in increased DP thymocyte numbers [31], whereas deficiency results in a mild decrease [32]. Thus, the upregulation of miR-181a is important for the DN4 to DP transition. miR-181a is thought to regulate the metabolic status of thymocytes by targeting Pten [32], a necessary determinant for the increased cell proliferation that accompanies the progression to the DP stage.

miR-181a has also been shown to modulate TCR signaling by targeting multiple negative regulators of signaling, including Dusp5, Dusp6 and Shp-2 [31]. Regulation of TCR signaling is critical for positive and negative selection, and can also affect lineage decision. miR-181a-deficient mice display a severe loss in NKT cells [32]. Disruption of NKT cell development had previously been observed when Dicer was deleted late in T cell development $[33,34]$. This suggests the NKT cell defect caused by Dicer deficiency is entirely due to miR-181a deficiency. Like the earlier DN4 to DP transition, the function of miR181a at this latter stage appears to involve the targeting of Pten and the regulation of metabolic status [32].

\section{Regulatory $\mathbf{T}$ cells}

While the NKT lineage was most dramatically affected by a lack of miRNAs late in T cell development, other $\alpha \beta T$ cell lineages were also affected to a varying extent. Foxp $3^{+}$ regulatory $\mathrm{T}$ cell (Treg) numbers were reduced with either Drosha or Dicer deficiency [26, 35]. The miRNA signature of Tregs is distinct from other $\mathrm{T}$ cells $[35,36]$. Whether specific miRNAs are responsible for thymic Treg differentiation or whether differentiation is simply a product of overall TCR regulation by miRNAs is still to be determined. One Treg-enriched miRNA that appears to contribute to this thymic differentiation is miR-155. miR-155deficient mice display a mild reduction in Foxp $3^{+}$cells in the thymus [37, 38]. miR-155 exerts its effect on Foxp3 expression, and Treg development by inhibiting Suppressor of cytokine signaling - 1 (SOCS1) [38], a negative regulator of JAK-STAT signaling.

Conventional naïve $\mathrm{CD} 4^{+} \mathrm{T}$ cells can also differentiate into Foxp $3^{+}$induced Tregs (iTregs), such as in response to transforming growth factor- $\beta$ (TGF $\beta$ ). This is also partially disrupted by Drosha or Dicer deficiency [26, 35] (Fig. 3). This induction of Foxp3 is at least partly dependent on miR-126 and miR-155. Regulation of SOCS1 by miR-155 appears to be involved again [39], while miR-126 


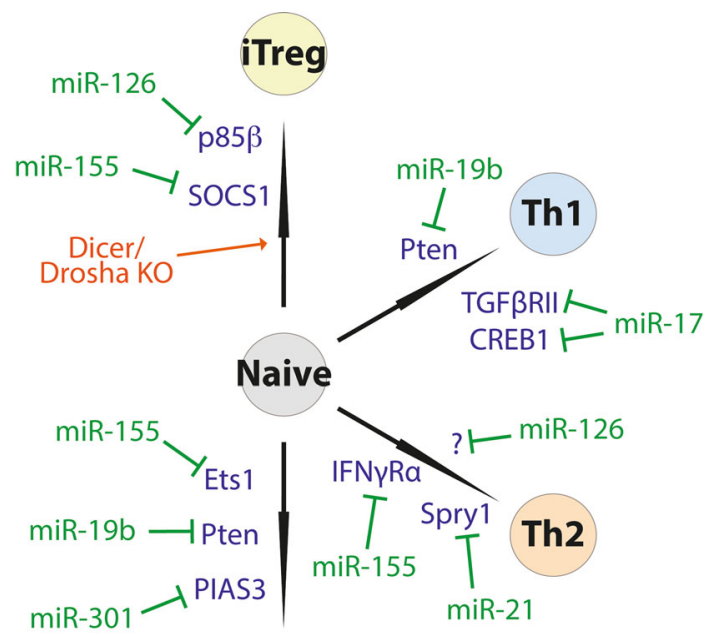

Th17

Fig. 3 MiRNAs and effector CD4 $+\mathrm{T}$ cell differentiation. Mature CD4 + helper T cells can differentiate into various flavors of effector $\mathrm{T}$ cells or induced regulatory $\mathrm{T}$ cells. Differentiation into the different subsets is dependent on specific miRNAs and the repression of specific targets. Also shown is the block caused by Drosha or Dicer deficiency. Th Helper T cell, iTreg induced regulatory $\mathrm{T}$ cell

is thought to act by inhibiting $\mathrm{p} 85 \beta$ and modulating the PI3 K/AKT pathway [40].

Not only is the miRNA pathway important for Treg differentiation, but it is also critical for the functional program of these cells. Tregs are necessary for maintaining immune homeostasis, and Treg deficiency, such as that caused by Foxp3 mutations, leads to lethal lymphoproliferation and inflammation in both mice and humans. Dicerl or Drosha gene inactivation specifically in Foxp $3^{+}$cells causes this same devastating lymphoproliferative disease $[26,41,42]$. However, unlike in Foxp3 deficient mice, the Foxp $3^{+}$cells are still present in these animals, but are essentially non-functional.

Several studies have since revealed the contribution of specific miRNAs for Treg function. miR-146a is enriched in Tregs, and deficiency causes a partial loss of Treg function [43]. Interestingly, it is the control of $\mathrm{T}$ helper 1 (Th1) responses that is specifically affected. STAT1 was found to be a target of miR-146a. miR-10 is another miRNA that is expressed in Tregs associated with Th1 responses, whereas miR-182 is expressed in Th2-associated Tregs [44]. Computational predictions suggest that miR-10 and miR-182 cross-regulate opposing networks of genes to promote the Th1- or Th2-associated phenotype.

In addition to its role in Treg differentiation, miR-155 is important for regulating the turnover of these cells and the maintenance of population size (or fitness) [38], but not for suppressor activity [37]. The miR-17-92a cluster of miRNAs has also been shown to be important for Treg fitness.
Several miRNAs derived from this polycistronic precursor are enriched in Tregs compared with other $\mathrm{T}$ cells [45]. Deletion of this gene specifically in the Tregs of mice causes a number of mild immunological perturbations. The cells display increased apoptosis and decreased proliferation [45], and impaired differentiation into IL-10-producing effector Tregs [46]. A primary function of this cluster is thought to be the regulation of lymphocyte survival [47], which is consistent with a phenotype of reduced fitness.

\section{Differentiation of Helper $\mathbf{T}$ cell subsets}

The differentiation of mature helper $\mathrm{T}$ cells into effector subsets is also modulated by specific miRNAs (Fig. 3). $\mathrm{CD}^{+}{ }^{+}$helper $\mathrm{T}$ cells can differentiate into one of a range of effector subsets (e.g., Th1, Th2, Th9, Th17, Th22), characterized by the expression of specific cytokines and transcription factors. In helper $\mathrm{T}$ cells, the miR-17-92a cluster is required for efficient Th1 differentiation, with miR-17 and miR-19b being the specific miRNAs of importance [48]. miR-17 promotes Th1 differentiation via the inhibition of TGF $\beta$ RII and CREB1, while miR-19b regulates Pten. This also prevents the differentiation of induced Tregs.

On the flip side, mir-155 is important for restraining Th1 differentiation by inhibiting IFN $\gamma$ R $\alpha$ expression [49]. Mice lacking this miRNA display a bias towards Th2 differentiation [49]. However, a second report found that miR-155deficient mice are resistant to experimental autoimmune encephalomyelitis (EAE), due to poor Th1 and Th17 differentiation [50]. The reason of this discrepancy is not clear, but may reflect different immunological contexts. Another autoimmune model that is dependent on Th17mediated responses, collagen-induced arthritis, is also suppressed in miR-155-deficient mice [51]. Thus, the poor Th1 differentiation in the context of EAE may be due to a dampened overall immune response.

miR-29a has also been found to inhibit Th1 differentiation and IFN $\gamma$ production. Deficiency results in unrestrained Th1 responses [52, 53]. A redirection to Th2 differentiation was not reported. miR-29a inhibits expression of the transcription factors T-bet and Eomesodermin that regulate IFN $\gamma$ gene expression [52, 54].

miR-21 promotes $\mathrm{Th} 2$ differentiation by inhibiting the expression of Spry1, a negative regulator of the MAP kinase pathway [55]. Increasing the expression of miR-21 enhances Gata3, IL-4, IL-5 and IL-13 expression by Th2 cells. Th2 differentiation is also influenced by miR-126. Blockade of miR-126 function with antagomirs impairs IL5 and IL-13 by Th2 cells [56], but the mechanism is not known. Whether these two miRNAs promote Th2 differentiation at the expense of other lineages is also unknown. 
Multiple miRNAs have been found to promote Th17 differentiation. As discussed above, miR-155 is necessary for the development of disease in Th17 animal models. miR-155 promotes Th17 differentiation by repressing the transcription factor Ets1 [57]. The miR-17-92a cluster is also required for effective Th17 differentiation. Like in Th1 cells, inhibition of Pten by miR-19b appears to be important, while miR-17 was found to regulate IKZF4 [58]. Given the ubiquitous expression of miR-17-92a miRNAs in all hematopoietic cells, it is not surprising to find a diverse range of functions for this cluster of miRNAs in $\mathrm{T}$ cells. miR-301 also participates in Th17 differentiation by repressing PIAS3, a negative regulator of STAT3 signaling [59].

\section{Regulation of B cell development}

One of the first indications that miRNAs may have important biological functions in mammals was in B cell development. B cell development occurs in the bone marrow, and overexpression of miR-181a was found to promote the differentiation of the B lineage [17]. Like T cells, the stages of B cell development can be identified by the expression of various cell surface markers, including immunoglobulins. Recombination of the immunoglobulin heavy chain locus occurs at the pro-B to early pre-B cell stages, followed by light-chain rearrangement at the late pre-B cell stage. Selection of cells with appropriate immunoglobulin expression then leads to $B$ cell maturation.

The first definitive proof that the miRNA pathway is necessary for the B lineage came when the Dicerl gene was deleted early in B cell development in mice. These mice exhibit a block at the pro-B to pre-B transition [60]. The terminal differentiation of mature $\mathrm{B}$ cells into antibody-producing cells or memory B cells is also dependent on Dicer [61]. This suggests that like T cell development, multiple steps in B cell development are dependent on miRNAs (Fig. 4). The requirement of the other RNase III enzyme, Drosha, has yet to be reported.

The miRNAs from the miR-17-92a cluster are clearly important for early B cell development. miR-17-92a deficient mice display a greatly reduced B cell compartment, with a developmental block at the pre-B cell stage [47]. This cluster of miRNAs was found to regulate B cell survival, in part, by repressing the proapoptotic molecule Bim. The fact that miR-17-92a deficiency only causes a partial block indicates that the severe block caused by Dicer deficiency is dependent on multiple miRNAs. On the other hand, overexpression of miR-34a has been shown to block $\mathrm{B}$ cell development at the pro-B to pre-B transition [62]. It

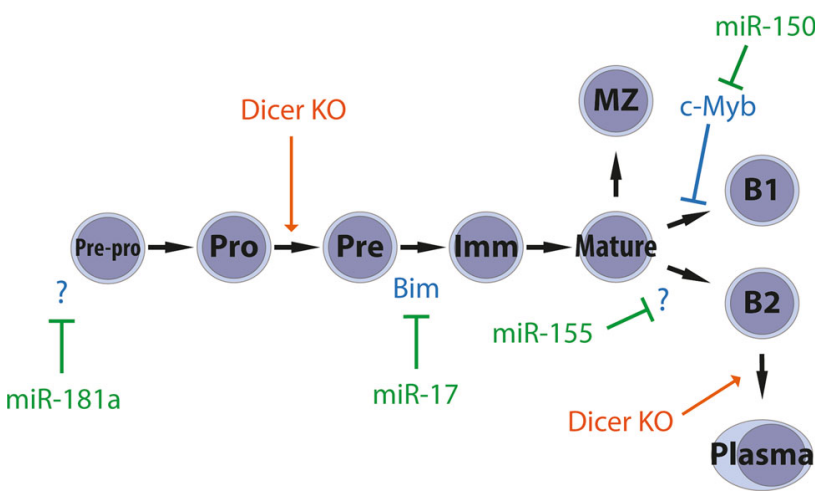

Fig. 4 MiRNA regulation of B lymphopoiesis. MiRNAs are also important regulators of $\mathrm{B}$ cell development. Indicated are miRNAs and their targets that have been found to be important. Also shown are developmental blocks caused by Dicer deficiency. $M Z$ marginal zone

was found to inhibit $\mathrm{B}$ lymphopoiesis by repressing the expression of Foxp1, a B cell oncogene that is required for the pro-B to pre-B transition [63].

The latter stages of B cell development are regulated by a number of different miRNAs. The differentiation of B1 cells is regulated by the transcription factor $\mathrm{c}-\mathrm{Myb}$, which in turn is regulated by miR-150. miR-150 deficiency results in a loss of c-Myb control and an expansion of B1 cells [64]. The differentiation of mature $\mathrm{B}$ cells into germinal center B cells is regulated by miR-155. B cells from miR155-deficient mice fail to express IgM or class switch, resulting is impaired antibody responses [65, 66].

\section{Other innate lymphocytes}

Innate lymphocytes are an expanding family of cells, which do not have the exquisite specificity of $\mathrm{T}$ or $\mathrm{B}$ cells but nevertheless fight infections, maintain homeostasis with commensal bacteria, maintain epithelial integrity and help organize lymphoid tissues. They include NK cells, nuocytes, MAIT cells and lymphoid tissue inducer cells. The ontogeny of NKT cells (which have a restricted $\mathrm{T}$ cell receptor and, therefore, appear to behave more like innate cells) is critically dependent on miR-181 [32]. Other than the differentiation of NKT cells, the role of miRNAs in the differentiation of innate lymphocyte populations is not as well understood. A handful of studies have indicated a potential role in NK cell differentiation. Deficiency in miR150 causes a reduction in mature cells in the periphery due to a loss of c-Myb repression [67]. miR-181a regulation of NLK, an inhibitor of Notch signaling, also contributes to NK cell differentiation [68]. The role of miRNAs in innate lymphocyte differentiation clearly remains a key area for further investigation. 


\section{Regulation of DC development}

Dendritic cells (DCs) are sentinel cells specializing in the capture and presentation of antigen to $\mathrm{T}$ cells, and can differentiate from both lymphoid and myeloid progenitors. DCs can be broadly divided into four major subsets, viz. tissue DCs (including epidermal Langerhans DCs, gut DCs, dermal DCs etc.), lymphoid-resident conventional DCs, plasmacytoid DCs and inflammatory DCs (monocytederived DCs). Early investigations into the role of miRNAs in DCs involved conditionally deleting Dicer in mature DCs with CD11c-cre, which had little impact on most DC populations [69]. However, deletion was never fully achieved in these mice because the half-life of miRNAs is longer than that of most mature DCs [70]. Whereas splenic DCs live for 3 days, Langerhans DCs can live for many months and as such the role of miRNAs on Langerhans cell homeostasis can be revealed. Indeed such cells are dramatically depleted in CD11c-dependent ablation of Dicer or Drosha.

To definitively assess if the miRNA pathway is necessary for DC development (other than Langerhans DCs) will require approaches that delete Dicerl and Drosha earlier. Nevertheless, a number of miRNAs have been implicated by means of knockdown or overexpression studies. This includes miR-22 that represses the transcription factor IRF8 [71], miR-21 and miR-34a that coordinately repress JAG1 and WNT1 [72], and miR-155 that represses p27kip1, KPC1, and SOCS-1 [73, 74]. Manipulating the expression of these miRNAs influences subset differentiation to varying degrees. The more rigorous studies of employing genetically modified mice to probe the roles of specific miRNAs are still somewhat lacking. One exception was the discovery that DC differentiation is partially disrupted in miR-142-deficient mice; this particularly affected $\mathrm{CD} 4^{+}$DCs [75].

In contrast to differentiation, a number of studies have demonstrated the importance of miRNAs for DC function. In addition to defects in DC differentiation, miR-142 deficiency impairs the ability of conventional DCs to prime $\mathrm{CD}^{+}{ }^{+}$helper $\mathrm{T}$ cells [75]. A similar phenotype was observed in miR-155-deficient mice [76]. Antigen presentation by Langerhans cells is also regulated by miRNAs. Langerhans cells from miR-150-deficient mice have reduced capacity to present exogenous antigens to cytotoxic $\mathrm{T}$ cells [77], whereas miR-223 deficiency enhances this process [78]. The mechanisms by which these miRNAs regulate antigen presentation are not known. As with the differentiation of these cells, knockdown and overexpression have implicated many more miRNAs in the regulation of DC function.

\section{Concluding remarks}

MiRNAs are without doubt critical regulators of cell differentiation, and lymphopoiesis pathways are prime examples where miRNAs exert important and diverse functions. However, we still have only a nominal understanding of how miRNAs regulate lymphopoiesis and much work remains, especially in regards to innate lymphocytes. There are several important considerations as we move forward. Many of the early studies investigating the potential role of the miRNA pathway relied on selective deletion of the Dicerl gene. Recent studies have revealed that the two RNase III enzymes central to miRNA biogenesis, Drosha and Dicer, have important functions beyond miRNA biogenesis (reviewed in [79]). Thus, it is possible that some of the phenotypes caused by Dicer deficiency may in fact be unrelated to miRNAs. A reevaluation of the role of miRNAs may be warranted in some cases, such as by analyzing the impact of deleting other key miRNA pathway genes. Understanding the specific miRNA-target networks involved will also be vital. However, because mismatching is an important feature of miRNA-mRNA interactions in animals, target prediction remains equivocal. Experimental validations will always to be essential, and the continued development of knockout mice for specific miRNAs will be particularly important.

Acknowledgments The authors are supported by grants and fellowships from the National Health and Medical Research Council, Australian Research Council, Juvenile Diabetes Research Foundation and Diabetes Australia Research Trust.

\section{References}

1. Lee RC, Feinbaum RL, Ambros V. The C. elegans heterochronic gene lin- 4 encodes small RNAs with antisense complementarity to lin-14. Cell. 1993;75:843-54.

2. Wightman B, Ha I, Ruvkun G. Posttranscriptional regulation of the heterochronic gene lin-14 by lin- 4 mediates temporal pattern formation in C. elegans. Cell. 1993;75:855-62.

3. Kozomara A, Griffiths-Jones S. miRBase: annotating high confidence microRNAs using deep sequencing data. Nucleic Acids Res. 2014;42:D68-73.

4. Krek A, Grun D, Poy MN, Wolf R, Rosenberg L, Epstein EJ, et al. Combinatorial microRNA target predictions. Nat Genet. 2005;37:495-500.

5. Friedman RC, Farh KK, Burge CB, Bartel DP. Most mammalian mRNAs are conserved targets of microRNAs. Genome Res. 2009;19:92-105.

6. Hammond SM, Boettcher S, Caudy AA, Kobayashi R, Hannon GJ. Argonaute2, a link between genetic and biochemical analyses of RNAi. Science. 2001;293:1146-50.

7. Dueck A, Ziegler C, Eichner A, Berezikov E, Meister G. microRNAs associated with the different human Argonaute proteins. Nucleic Acids Res. 2012;40:9850-62. 
8. Lewis BP, Shih IH, Jones-Rhoades MW, Bartel DP, Burge CB. Prediction of mammalian microRNA targets. Cell. 2003;115:787-98.

9. Lai EC. Micro RNAs are complementary to $3^{\prime}$ UTR sequence motifs that mediate negative post-transcriptional regulation. Nat Genet. 2002;30:363-4.

10. Lewis BP, Burge CB, Bartel DP. Conserved seed pairing, often flanked by adenosines, indicates that thousands of human genes are microRNA targets. Cell. 2005;120:15-20.

11. Huntzinger E, Izaurralde E. Gene silencing by microRNAs: contributions of translational repression and mRNA decay. Nat Rev Genet. 2011;12:99-110.

12. Lee Y, Ahn C, Han J, Choi H, Kim J, Yim J, et al. The nuclear RNase III Drosha initiates microRNA processing. Nature. 2003;425:415-9.

13. Denli AM, Tops BB, Plasterk RH, Ketting RF, Hannon GJ. Processing of primary microRNAs by the Microprocessor complex. Nature. 2004;432:231-5.

14. Gregory RI, Yan KP, Amuthan G, Chendrimada T, Doratotaj B, Cooch N, et al. The Microprocessor complex mediates the genesis of microRNAs. Nature. 2004;432:235-40.

15. Chendrimada TP, Gregory RI, Kumaraswamy E, Norman J, Cooch N, Nishikura K, et al. TRBP recruits the Dicer complex to Ago 2 for microRNA processing and gene silencing. Nature. 2005;436:740-4.

16. Forstemann K, Tomari Y, Du T, Vagin VV, Denli AM, Bratu DP, et al. Normal microRNA maturation and germ-line stem cell maintenance requires Loquacious, a double-stranded RNA-binding domain protein. PLoS Biol. 2005;3:e236.

17. Chen CZ, Li L, Lodish HF, Bartel DP. MicroRNAs modulate hematopoietic lineage differentiation. Science. 2004;303:83-6.

18. Guo S, Lu J, Schlanger R, Zhang H, Wang JY, Fox MC, et al. MicroRNA miR-125a controls hematopoietic stem cell number. Proc Natl Acad Sci USA. 2010;107:14229-34.

19. Gruber JJ, Zatechka DS, Sabin LR, Yong J, Lum JJ, Kong M, et al. Ars2 links the nuclear cap-binding complex to RNA interference and cell proliferation. Cell. 2009;138:328-39.

20. Han YC, Park CY, Bhagat G, Zhang J, Wang Y, Fan JB, et al. microRNA-29a induces aberrant self-renewal capacity in hematopoietic progenitors, biased myeloid development, and acute myeloid leukemia. J Exp Med. 2010;207:475-89.

21. Popovic R, Riesbeck LE, Velu CS, Chaubey A, Zhang J, Achille NJ, et al. Regulation of mir-196b by MLL and its overexpression by MLL fusions contributes to immortalization. Blood. 2009;113:3314-22.

22. Ooi AG, Sahoo D, Adorno M, Wang Y, Weissman IL, Park CY. MicroRNA-125b expands hematopoietic stem cells and enriches for the lymphoid-balanced and lymphoid-biased subsets. Proc Natl Acad Sci USA. 2010;107:21505-10.

23. Cobb BS, Nesterova TB, Thompson E, Hertweck A, O'Connor E, Godwin $\mathrm{J}$, et al. $\mathrm{T}$ cell lineage choice and differentiation in the absence of the RNase III enzyme Dicer. J Exp Med. 2005;201:1367-73.

24. Chong MM, Zhang G, Cheloufi S, Neubert TA, Hannon GJ, Littman DR. Canonical and alternate functions of the microRNA biogenesis machinery. Genes Dev. 2010;24:1951-60.

25. Muljo SA, Ansel KM, Kanellopoulou C, Livingston DM, Rao A, Rajewsky K. Aberrant $\mathrm{T}$ cell differentiation in the absence of Dicer. J Exp Med. 2005;202:261-9.

26. Chong MM, Rasmussen JP, Rudensky AY, Littman DR. The RNAseIII enzyme Drosha is critical in T cells for preventing lethal inflammatory disease. J Exp Med. 2008;205:2005-17.

27. Thompson PK, Zuniga-Pflucker JC. On becoming a T cell, a convergence of factors kick it up a Notch along the way. Semin Immunol. 2011;23:350-9.
28. Ghisi M, Corradin A, Basso K, Frasson C, Serafin V, Mukherjee $\mathrm{S}$, et al. Modulation of microRNA expression in human $\mathrm{T}$-cell development: targeting of NOTCH3 by miR-150. Blood. 2011;117:7053-62.

29. Belkaya S, Murray SE, Eitson JL, de la Morena MT, Forman JA, van Oers NS. Transgenic expression of microRNA-185 causes a developmental arrest of $\mathrm{T}$ cells by targeting multiple genes including Mzb1. J Biol Chem. 2013;288:30752-62.

30. Neilson JR, Zheng GX, Burge CB, Sharp PA. Dynamic regulation of miRNA expression in ordered stages of cellular development. Genes Dev. 2007;21:578-89.

31. Li QJ, Chau J, Ebert PJ, Sylvester G, Min H, Liu G, et al. miR181a is an intrinsic modulator of $\mathrm{T}$ cell sensitivity and selection. Cell. 2007;129:147-61.

32. Henao-Mejia J, Williams A, Goff LA, Staron M, Licona-Limon $\mathrm{P}$, Kaech SM, et al. The microRNA miR-181 is a critical cellular metabolic rheostat essential for NKT cell ontogenesis and lymphocyte development and homeostasis. Immunity. 2013;38:984-97.

33. Fedeli M, Napolitano A, Wong MP, Marcais A, de Lalla C, Colucci $\mathrm{F}$, et al. Dicer-dependent microRNA pathway controls invariant NKT cell development. J Immunol. 2009;183:2506-12.

34. Seo KH, Zhou L, Meng D, Xu J, Dong Z, Mi QS. Loss of microRNAs in thymus perturbs invariant NKT cell development and function. Cell Mol Immunol. 2010;7:447-53.

35. Cobb BS, Hertweck A, Smith J, O’Connor E, Graf D, Cook T, et al. A role for Dicer in immune regulation. J Exp Med. 2006;203:2519-27.

36. Kuchen S, Resch W, Yamane A, Kuo N, Li Z, Chakraborty T, et al. Regulation of microRNA expression and abundance during lymphopoiesis. Immunity. 2010;32:828-39.

37. Kohlhaas S, Garden OA, Scudamore C, Turner M, Okkenhaug K, Vigorito E. Cutting edge: the Foxp3 target miR-155 contributes to the development of regulatory $\mathrm{T}$ cells. $\mathrm{J}$ Immunol. 2009; 182:2578-82.

38. Lu LF, Thai TH, Calado DP, Chaudhry A, Kubo M, Tanaka K, et al. Foxp3-dependent microRNA155 confers competitive fitness to regulatory $\mathrm{T}$ cells by targeting SOCS1 protein. Immunity. 2009;30:80-91.

39. Yao R, Ma YL, Liang W, Li HH, Ma ZJ, Yu X, et al. MicroRNA155 modulates Treg and Th17 cells differentiation and Th17 cell function by targeting SOCS1. PLoS One. 2012;7:e46082.

40. Qin A, Wen Z, Zhou Y, Li Y, Li Y, Luo J, et al. MicroRNA-126 regulates the induction and function of $\mathrm{CD}^{+}{ }^{+} \mathrm{Foxp}^{+}$regulatory $\mathrm{T}$ cells through PI3 K/AKT pathway. J Cell Mol Med. 2013;17:252-64.

41. Zhou X, Jeker LT, Fife BT, Zhu S, Anderson MS, McManus MT, et al. Selective miRNA disruption in $\mathrm{T}$ reg cells leads to uncontrolled autoimmunity. J Exp Med. 2008;205:1983-91.

42. Liston A, Lu LF, O'Carroll D, Tarakhovsky A, Rudensky AY. Dicer-dependent microRNA pathway safeguards regulatory $\mathrm{T}$ cell function. J Exp Med. 2008;205:1993-2004.

43. Lu LF, Boldin MP, Chaudhry A, Lin LL, Taganov KD, Hanada $\mathrm{T}$, et al. Function of miR-146a in controlling Treg cell-mediated regulation of Th1 responses. Cell. 2010;142:914-29.

44. Kelada S, Sethupathy P, Okoye IS, Kistasis E, Czieso S, White $\mathrm{SD}$, et al. miR-182 and miR-10a are key regulators of Treg specialisation and stability during Schistosome and Leishmaniaassociated inflammation. PLoS Pathog. 2013;9:e1003451.

45. Skinner JP, Keown AA, Chong MM. The miR-17-92a cluster of MicroRNAs is required for the fitness of $\mathrm{Foxp}^{+}$regulatory $\mathrm{T}$ cells. PLoS One. 2014;9:e88997.

46. de Kouchkovsky D, Esensten JH, Rosenthal WL, Morar MM, Bluestone JA, Jeker LT. microRNA-17-92 regulates IL-10 production by regulatory $\mathrm{T}$ cells and control of experimental autoimmune encephalomyelitis. J Immunol. 2013;191:1594-605. 
47. Ventura A, Young AG, Winslow MM, Lintault L, Meissner A, Erkeland SJ, et al. Targeted deletion reveals essential and overlapping functions of the miR-17-92 family of miRNA clusters. Cell. 2008;132:875-86.

48. Jiang S, Li C, Olive V, Lykken E, Feng F, Sevilla J, et al. Molecular dissection of the miR-17-92 cluster's critical dual roles in promoting Th1 responses and preventing inducible Treg differentiation. Blood. 2011;118:5487-97.

49. Banerjee A, Schambach F, DeJong CS, Hammond SM, Reiner SL. Micro-RNA-155 inhibits IFN- $\gamma$ signaling in CD4 $+\mathrm{T}$ cells. Eur J Immunol. 2010;40:225-31.

50. O'Connell RM, Kahn D, Gibson WS, Round JL, Scholz RL, Chaudhuri AA, et al. MicroRNA-155 promotes autoimmune inflammation by enhancing inflammatory $\mathrm{T}$ cell development. Immunity. 2010;33:607-19.

51. Kurowska-Stolarska M, Alivernini S, Ballantine LE, Asquith DL, Millar NL, Gilchrist DS, et al. MicroRNA-155 as a proinflammatory regulator in clinical and experimental arthritis. Proc Natl Acad Sci USA. 2011;108:11193-8.

52. Smith KM, Guerau-de-Arellano M, Costinean S, Williams JL, Bottoni A, Mavrikis Cox G, et al. miR-29ab1 deficiency identifies a negative feedback loop controlling Th1 bias that is dysregulated in multiple sclerosis. J Immunol. 2012;189:1567-76.

53. Ma F, Xu S, Liu X, Zhang Q, Xu X, Liu M, et al. The microRNA miR-29 controls innate and adaptive immune responses to intracellular bacterial infection by targeting interferon- $\gamma$. Nat Immunol. 2011;12:861-9.

54. Steiner DF, Thomas MF, Hu JK, Yang Z, Babiarz JE, Allen CD, et al. MicroRNA-29 regulates T-box transcription factors and interferon $\gamma$ production in helper $\mathrm{T}$ cells. Immunity. 2011;35:169-81.

55. Sawant DV, Wu H, Kaplan MH, Dent AL. The Bcl6 target gene microRNA-21 promotes Th2 differentiation by a $\mathrm{T}$ cell intrinsic pathway. Mol Immunol. 2013;54:435-42.

56. Mattes J, Collison A, Plank M, Phipps S, Foster PS. Antagonism of microRNA-126 suppresses the effector function of TH2 cells and the development of allergic airways disease. Proc Natl Acad Sci USA. 2009;106:18704-9.

57. Hu R, Huffaker TB, Kagele DA, Runtsch MC, Bake E, Chaudhuri AA, et al. MicroRNA-155 confers encephalogenic potential to Th17 cells by promoting effector gene expression. J Immunol. 2013;190:5972-80.

58. Liu SQ, Jiang S, Li C, Zhang B, Li QJ. miR-17-92 cluster targets phosphatase and tensin homology and Ikaros family zinc finger 4 to promote TH17-mediated inflammation. J Biol Chem. 2014;289:12446-56.

59. Mycko MP, Cichalewska M, Machlanska A, Cwiklinska H, Mariasiewicz M, Selmaj KW. MicroRNA-301a regulation of a T-helper 17 immune response controls autoimmune demyelination. Proc Natl Acad Sci USA. 2012;109:E1248-57.

60. Koralov SB, Muljo SA, Galler GR, Krek A, Chakraborty T, Kanellopoulou C, et al. Dicer ablation affects antibody diversity and cell survival in the B lymphocyte lineage. Cell. 2008;132:860-74.

61. Xu S, Guo K, Zeng Q, Huo J, Lam KP. The RNase III enzyme Dicer is essential for germinal center B-cell formation. Blood. 2012;119:767-76.

62. Rao DS, O'Connell RM, Chaudhuri AA, Garcia-Flores Y, Geiger TL, Baltimore D. MicroRNA-34a perturbs B lymphocyte development by repressing the forkhead box transcription factor Foxp1. Immunity. 2010;33:48-59.
63. Hu H, Wang B, Borde M, Nardone J, Maika S, Allred L, et al. Foxp1 is an essential transcriptional regulator of B cell development. Nat Immunol. 2006;7:819-26.

64. Xiao C, Calado DP, Galler G, Thai TH, Patterson HC, Wang J, et al. MiR-150 controls B cell differentiation by targeting the transcription factor c-Myb. Cell. 2007;131:146-59.

65. Thai TH, Calado DP, Casola S, Ansel KM, Xiao C, Xue Y, et al. Regulation of the germinal center response by microRNA-155. Science. 2007;316:604-8.

66. Rodriguez A, Vigorito E, Clare S, Warren MV, Couttet P, Soond $\mathrm{DR}$, et al. Requirement of bic/microRNA-155 for normal immune function. Science. 2007;316:608-11.

67. Bezman NA, Chakraborty T, Bender T, Lanier LL. miR-150 regulates the development of NK and iNKT cells. J Exp Med. 2011;208:2717-31.

68. Cichocki F, Felices M, McCullar V, Presnell SR, Al-Attar A, Lutz CT, et al. Cutting edge: microRNA-181 promotes human NK cell development by regulating Notch signalling. J Immunol. 2011;187:6171-5.

69. Kuipers H, Schnorfeil FM, Fehling HJ, Bartels H, Brocker T. Dicer-dependent microRNAs control maturation, function, and maintenance of Langerhans cells in vivo. $\mathrm{J}$ Immunol. 2010;185:400-9.

70. Gantier MP, McCoy CE, Rusinova I, Saulep D, Wang D, Xu D, et al. Analysis of microRNA turnover in mammalian cells following Dicer1 ablation. Nucleic Acids Res. 2011;39:5692-703.

71. Li HS, Greeley N, Sugimoto N, Liu YJ, Watowich SS. miR-22 controls Irf8 mRNA abundance and murine dendritic cell development. PLoS One. 2012;7:e52341.

72. Hashimi ST, Fulcher JA, Chang MH, Gov L, Wang S, Lee B. MicroRNA profiling identifies miR-34a and miR-21 and their target genes JAG1 and WNT1 in the coordinate regulation of dendritic cell differentiation. Blood. 2009;114:404-14.

73. Lu C, Huang X, Zhang X, Roensch K, Cao Q, Nakayama KI, et al. miR-221 and miR-155 regulate human dendritic cell development, apoptosis, and IL-12 production through targeting of p27kip1, KPC1, and SOCS-1. Blood. 2011;117:4293-303.

74. Kuipers H, Schnorfeil FM, Brocker T. Differentially expressed microRNAs regulate plasmacytoid vs. conventional dendritic cell development. Mol Immunol. 2010;48:333-40.

75. Mildner A, Chapnik E, Manor O, Yona S, Kim KW, Aychek T, et al. Mononuclear phagocyte miRNome analysis identifies miR142 as critical regulator of murine dendritic cell homeostasis. Blood. 2013;121:1016-27.

76. Ceppi M, Pereira PM, Dunand-Sauthier I, Barras E, Reith W, Santos MA, et al. MicroRNA-155 modulates the interleukin-1 signalling pathway in activated human monocyte-derived dendritic cells. Proc Natl Acad Sci USA. 2009;106:2735-40.

77. Mi QS, Xu YP, Qi RQ, Shi YL, Zhou L. Lack of microRNA miR150 reduces the capacity of epidermal Langerhans cell crosspresentation. Exp Dermatol. 2012;21:876-7.

78. Mi QS, Xu YP, Wang H, Qi RQ, Dong Z, Zhou L. Deletion of microRNA miR-223 increases Langerhans cell cross-presentation. Int J Biochem Cell Biol. 2013;45:395-400.

79. Johanson TM, Lew AM, Chong MM. MicroRNA-independent roles of the RNase III enzymes Drosha and Dicer. Open Biol. 2013;3:130144. 